\title{
Comparison of P53 Intensity, Frequency and Size in Normal Skin Periphery of Squamous Cell Carcinoma, Basal Cell Carcinoma And Melanocytic Nevus in Persian Skin Type
}

\author{
Farahnaz Bidari Zerehpoosh ${ }^{1}$, Soheila Nasiri ${ }^{2}$, Sara Zahedifard ${ }^{3}$, Shahram Sabeti ${ }^{1 *}$ \\ 1. Dept. of Pathology, Loghman Hakim Hospital, Shahid Beheshti Medical University of Sciences, Tehran, Iran \\ 2. Skin Research Center, Shahid Beheshti Medical University of Sciences, Tehran, Iran \\ 3. Dept. of Pathology, Saveh Medical University of Sciences, Saveh, Iran
}

\begin{tabular}{l} 
KEYWORDS \\
\hline Carcinoma \\
Squamous \\
Basal cell \\
P53 Antigen \\
Skin \\
\\
\hline
\end{tabular}

Article Info

Received 12 Oct 2015;

Accepted 11 Apr 2016;

Published Online 30 Aug 2016;

\section{ABSTRACT}

Background: Non-Melanoma Skin Cancer (NMSC), the most prevalent types being Squamous Cell Carcinoma (SCC) and Basal Cell Carcinoma (BCC), is the most common type of malignancy in human beings. These neoplasms are more frequent in the elderly and fair skinned people and mainly occur on sun-exposed sites of the body. Ultraviolet B (UVB) has a well-known effect in induction and promotion of growth of these cancers. The p53 tumor suppressor gene is believed to be an early target in UV-induced skin carcinogenesis. Aggregates of keratinocytes with p53 protein overexpression are frequently identified in normal human skin and are more prevalent in chronically sun-exposed skin, and have been proposed to play a role in skin cancer pathogenesis. The aim of this study was to clarify the potential role of P53 in the development of NMSC.

Methods: Immunohistochemical evaluation of p53 expression in peri-lesional skin of 90 cases of SCC, BCC and melanocytic nevi was performed.

Results: The well-delineated compact type of p53 clone, but not the strong dispersed type, was significantly more predominant in SCCs in comparison with BCCs and melanocytic nevi ( $\mathrm{P}$ value=0.001). The size of p53 clones was also significantly greater in SCCs compared to the BCCs $(\mathrm{P}=0.003)$ and melanocytic nevi $(\mathrm{P}=0.001)$. There was no significant difference between these neoplasms regarding the frequency of P53 clones $(\mathrm{P}=0.86)$.

Conclusion: This study suggests the possible relationship of epidermal p53 clones with the pathogenesis of SCC.

Corresponding Information: Dr. Shahram Sabeti. Dept. of Pathology, Loghman Hakim Hospital, Shahid Beheshti Medical University of Sciences, Tehran, Iran. Tel: +989122365023 Email: s_sabeti@ sbmu.ac.ir

Copyright ( 2017 , IRANIAN JOURNAL OF PATHOLOGY. This is an open-access article distributed under the terms of the Creative Commons Attribution-noncommercial 4.0 International License which permits copy and redistribute the material just in noncommercial usages, provided the original work is properly cited.

\section{Introduction}

Non-Melanoma Skin Cancer (NMSC), the most common types being Basal Cell Carcinoma (BCC) and Squamous Cell Carcinoma (SCC), is the most common form of malignancy in human beings, with over one million new cases reported in the United States each year (1-3). In contrast to basal cell carcinomas, SCCs characteristically have a high potency for aggressive behavior and can be lethal (1, 2). Basal Cell Carcinomas are probably related to recreational or occupational exposure to sunlight, whereas SCCs are linked to cumulative exposure to sunlight throughout life (4).

Ultraviolet radiation has a known effect in damaging DNA of epidermal cells. The risk of skin cancer is associated with exposure to UV radiation, with UVB being the most important risk factor (5). The p53 tumor suppressor gene (also known as TP53), which is frequently mutated in cancers of human beings, is presumably involved in UV radiation-induced skin carcinogenesis (6). 
The human p53 mutations are detected in nonmelanoma skin cancers with a high frequency. Sunlight normally induces Cyclobutane Pyrimidine Dimer (CPDs) formation; occurrence of this dimer with different sequence distribution coincides with loss of DNA repair process, resulting in proliferation of malignant cells. These events are found in diverse skin malignancies (7).

A transcription factor named Activating Transcription Factor 3 (AFT3) results in skin malignancy via modulation of p53 activated Signal Transducer and Activator of Transcription 3 (STAT3) phosphorylation. This means that ATF3 induces skin cancers by inhibiting P53 expression and then activating STAT3. The mutated P53 protein accumulates in the nucleus, which is demonstrated by immunohistochemistry (8).

Regarding the frequent finding of P53 mutation in precancerous lesions, it is probably an early event in skin carcinogenesis (9).

The mutated forms of P53 in human cutaneous SCCs show C-T transitions at dipyrimidine sites, particularly CC-TT double base changes. These mutations are not demonstrable in systemic SCCs. These are fingerprints for UV damage and further indicate the role of UV radiation in skin carcinogenesis (10).

Exposure to UV radiation induces p53 expression in scattered epidermal keratinocytes, which is a normal response to DNA damage and its role is DNA repair or apoptosis induction. However, the chronically sun-damaged skin shows clusters of morphologically normal $\mathrm{P}^{+}{ }^{+}$keratinocytes named "epidermal P53 clones"(4). In prior investigations on the effect of UVB exposure on the skin of mouse, an increment in the size and number of clones was shown during repeated exposure to UVB; cessation of this exposure was followed by a decrease in the number of clones but not in their size (10).

Expansion of P53-mutated keratinocytes is the result of relative resistance of cells in a clone against apoptosis (11). This resistance is the consequence of the loss of P53 function and resultant impaired control of the cell cycle.
Several studies have been performed to indicate the role of epidermal P53 clones in NMSC pathogenesis (4,11-13).

The aim of this study was to assess and compare the number, size and intensity of staining of P53 clones in peri-lesional normal epidermis of SCCs, BCCs and melanocytic nevi.

\section{Materials and Methods}

\section{Samples}

The pathology registry of Loghman Hakim Hospital was used to retrieve 90 cases, 30 cases each, of SCC, BCC and melanocytic nevus of facial skin with the permission of the ethics committee of the skin research center, affiliated to the Shahid Beheshti University of Medical Sciences. The relevant Haematoxylin and Eosin (H\&E)-stained slides were assessed independently by two pathologists to verify the diagnosis and determine the adequacy of the adjacent normal epidermis. Normal epidermal component of melanocytic nevi was used as the control.

\section{Immunohistochemistry}

Formalin-fixed, paraffin-embedded tissue samples were cut in 5- $\mu \mathrm{m}$ thick sections. Sections were deparaffinized in xylene and rehydrated in a series of graded alcohol. Sections were embedded in $0.01 \mathrm{~mole} / \mathrm{l}$ citrate buffer $(\mathrm{PH}=6)$, placed in a microwave at $800 \mathrm{~W}$, until boiling of the buffer and kept thereafter for 2 minutes under the boiling conditions. Then, sections and buffer were brought to room temperature, followed by another 2 minutes of boiling in citrate buffer. For detection and visualization of P53 protein, the primary p53 antibody (RTU-p53-Clone D07, Novocastra, UK) and Novolink polymer detection system (Novocastra, RE7140-K) were used. Positive and negative controls were included for each staining run. The positive and negative controls were "weakly positive breast carcinoma" and "cerebellum", respectively.

\section{Scoring of P53 staining}

The Immunohistochemistry (IHC)-stained slides were examined under magnifications of $\times 100$ and $\times 400$ of microscope, the p53 clones were detected and their size, type and frequency were quantified. 
The two major p53 staining patterns were "strong but dispersed", designated as type1, and "compact well-delineated", designated as type 2 (Figs.1\&2) (4). The size of p53 clones was recorded as the total length of clones in a section in millimeters, irrespective of their thickness. The total length of epidermis in each section was measured as well.

\section{Statistical analysis}

The Mann-Whitney U-test, Kruskal-Wallis oneway analysis of variance and logistic regression analysis were used for comparison of the frequency, size and type of p53 epidermal clones between neoplastic groups.

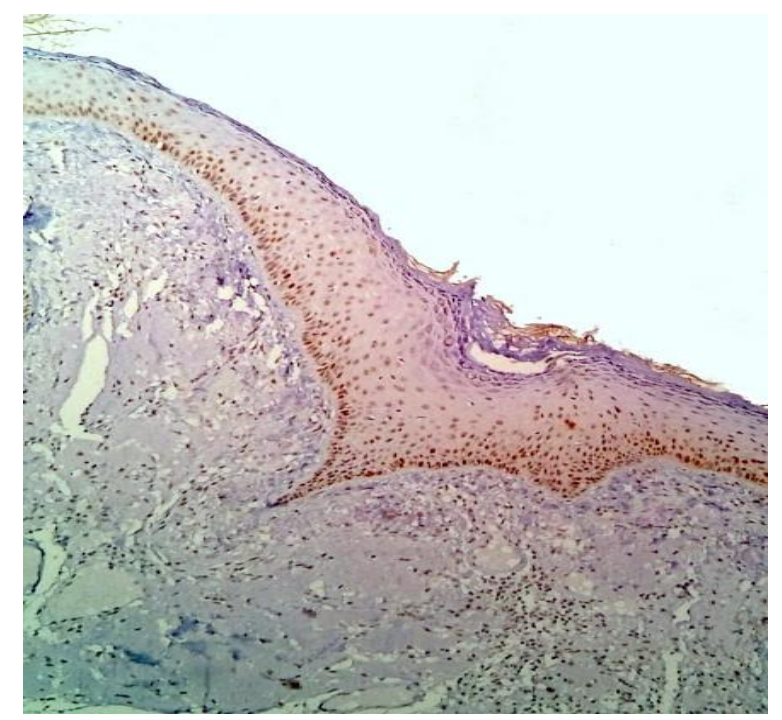
$(\times 100)$

Fig. 1. Weak Epidermal P53 Staining Intensity

Table 1. Frequency of p53 Clones $\mathrm{mm}^{-1}$ of Normal Peri-Lesional Skin of Basal Cell Carcinoma (BCC) and Squamous Cell Carcinoma (SCC) and Melanocytic Nevi

\begin{tabular}{|ccccccc|}
\hline & Number of cases & Minimum & First quarter & Median & $\mathbf{3}^{\text {rd }}$ quarter & Maximum \\
\hline BCC & 30 & 0.00 & 0.10 & 0.12 & 0.20 & $\mathbf{0 . 3 3}$ \\
\hline SCC & 30 & 0.05 & 0.10 & 0.12 & 0.19 & $\mathbf{0 . 5 7}$ \\
\hline Melanocytic nevus & 30 & 0.00 & 0.00 & 0.13 & 0.20 & $\mathbf{0 . 4 0}$ \\
\hline
\end{tabular}

As shown in Tables 2 and 3, types of p53 clones were significantly different, with type 2 predominating, in SCCs relative to both BCCs and melanocytic nevi $(\mathrm{p}<0.001)$.

At last, size of the $\mathrm{p} 53$ clones was greater in perilesional skin of SCCs relative to that of BCCs $(\mathrm{P}=0.003)$. Meanwhile, a meaningful difference was found between SCCs and melanocytic nevi $(\mathrm{p}<0.001)$ (Table 4).

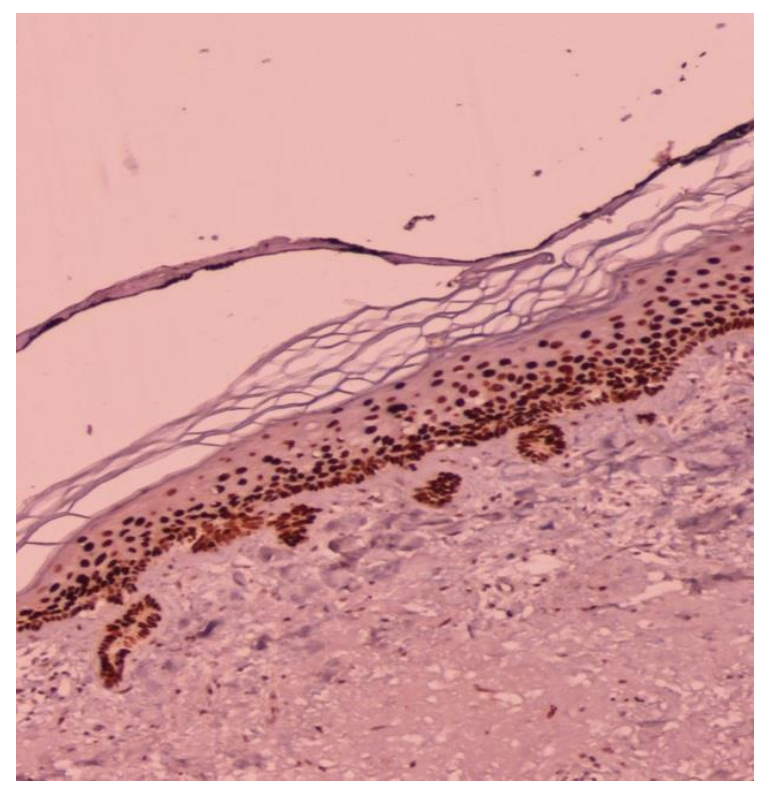

Fig. 2. Strong Epidermal P53 Staining Intensity $(\times 100)$

\section{Results}

One hundred thirty one (131) epidermal p53 clones were counted in $985 \mathrm{~mm}$ of normal perilesional facial skin. The data of p53 clone frequency, type and size have been shown on separate tables.

There was no significant difference in the frequency of p53 clones in the skin adjacent to SCCs in comparison to the normal skin surrounding BCCs and melanocytic nevi $(\mathrm{p}=0.86)$ (Table 1$)$. 
Table 3. Logistic regression analysis of each group regarding to p53 clone typing

\begin{tabular}{|lcc}
\hline & Ordinal Odds Ratio (95\% CI) & P-value \\
\hline SCC (in comparison to melanocytic nevus) & $12.00(2.85-50.59)$ & 0.001 \\
\hline BCC (in comparison to melanocytic nevus) & $1.71(0.37-7.85)$ & 0.49 \\
\hline
\end{tabular}

Table. 4. Statistics of p53 clone size ( $\mathrm{mm})$ in SCCs, BCCs and melanocytic nevi

\begin{tabular}{|c|c|c|c|c|c|c|}
\hline & number & minimum & $1^{\text {st }}$ quarter & Median & $3^{\text {rd }}$ quarter & maximum \\
\hline BCC & 30 & 0.00 & 1.00 & 1.00 & 3.00 & 8.00 \\
\hline $\mathrm{SCC}$ & 30 & 0.50 & 1.00 & 3.00 & 6.00 & 10.00 \\
\hline Melanocytic nevus & 30 & 0.00 & 0.50 & 1.00 & 2.00 & 5.00 \\
\hline
\end{tabular}

\section{Discussion}

Carcinogenesis is a complicated process resulting from the accumulation of critical genetic changes, some of them known as "molecular signatures" with a direct relationship to specific carcinogens. It has been proposed that these molecular signatures can be regarded as dosimeters of cumulative exposure to carcinogens and predictors of cancer risk. Skin cancer is a good sample for assessment of molecular signatures because it is strongly associated with UV radiation (6). The association of epidermal p53 clones and mutations with certain types of skin cancer such as SCC and BCC has been reported in prior studies. Thus, p53 can be regarded as an early target in skin carcinogenesis (4). Most of the investigations on epidermal p53 clones have been performed on mouse skin.

Our investigation was performed on 90 randomly selected cases of SCC, BCC and melanocytic nevus, 30 cases each, to assess the size, frequency and type of p53 clones in morphologically normal perilesional skin and their difference in these neoplasms. The melanocytic nevi were used as a control in this study.

We found significantly greater size and increased frequency of compact (type 2) p53 clones in the epidermis adjacent to SCCs relative to BCCs and melanocytic nevi. The difference of these parameters between BCCs and melanocytic nevi was insignificant. These findings indicate a link between p53 clone size and type with SCC, yet not BCC. This is in accordance with prior studies on mice (12) and somewhat with that performed on humans (4).
Prior studies based on Polymerase Chain Reaction (PCR) and direct gene sequencing have shown p53 mutations in keratinocytes of the normal skin surrounding NMSCs, most of them showing UV signature (14).

Some of the investigations, such as the study performed by Backvall et al. (4), showed higher frequency of mutations in epidermal p53 clones in SCCs, which was not the case in our study. This discrepancy may be the result of a difference in the Fitzpatrick skin type, which was predominantly of type 3 in our study, representative of the Middle Eastern population. In the investigation of Ouhtitt et al. (6), frequency of P53 mutations was shown to be greater in BCCs, which is in contrary of our investigation. In the latter investigation, preparation of the biopsy sample from the mirror image site to the neoplasm, instead of its vicinity, could be the source of difference.

\section{Conclusion}

In conclusion, we suggest that epidermal p53 clones may have a role in the pathogenesis of squamous cell carcinoma, but not Basal Cell Carcinoma.

\section{Acknowledgment:}

The current research project was supported financially by Skin Research Center affiliated to Shahid Beheshti University of Medical Sciences, Tehran, Iran.

Conflict of Interest: The authors declare that there was no conflict of interest. 


\section{References}

1. Kumar, R., Deep, G., \& Agarwal, R. An Overview of Ultraviolet B Radiation-Induced Skin Cancer Chemoprevention by Silibinin. Current Pharmacology Reports 2015; 1(3):206-215.

2. Albert MR, Weinstock MA. Keratinocyte carcinoma. CA Cancer J Clin 2003 ;53(5):292-302

3. Nikolaou, V., Stratigos, A. J., \& Tsao, H. Hereditary nonmelanoma skin cancer. In Seminars in cutaneous medicine and surgery 2012. NIH Public Access;31(4): 204.

4. Backvall $\mathrm{H}$, Wolf $\mathrm{O}$, Hermelin $\mathrm{H}$, Weitzberg $\mathrm{E}$, Ponten F. The density of epidermal p53 clones is higher adjacent to squamous cellcarcinoma in comparison with basal cell carcinoma. $\mathrm{Br} \mathrm{J}$ Dermatol 2004;150(2):259-66

5. Weedon D, Strutton G, Rubin A.I. Tumors of the epidermis. In: Weedon D, Strutton G, Rubin A.I. Weedon's skin pathology. 4th edition. China: Churchill Livingstone Elsevier; 2016. P.816.

6. Ouhtit A, Nakazawa H, Armstrong BK, Kricker A, Tan E, Yamasaki H, et al. UV-radiationspecific p53 mutation frequency in normal skin as a predictor of risk of basal cell carcinoma. J Natl Cancer Inst 1998;90(7):523-31

7. Hao, Z. F., Ao, J. H., Zhang, J., Su, Y. M., \& Yang, R. Y. ATF3 activates Stat3 phosphorylation through inhibition of p53 expression in skin cancer cells. Asian Pac J Cancer Prev 2013;14, 7439-44.

8. Pfeifer, G. P., \& Besaratinia, A. (2012). UV wavelength-dependent DNA damage and human non-melanoma and melanoma skin cancer. Photochemical \& Photobiological Sciences 2012; 11(1): 90-97.
9. Ziegler A, Jonason AS, Leffell DJ, Simon JA, Sharma HW, Kimmelman J, et al. Sunburn and p53 in the onset of skin cancer. Nature 1994 22;372(6508):773-6

10. Zhang W, Remenyik E, Zelterman D, Brash DE, Wikonkal NM. Escaping the stem cell compartment: sustained UVB exposure allows p53mutant keratinocytes to colonize adjacent epidermal proliferating units without incurring additional mutations. Proceedings of the National Academy of Sciences. 2001 Nov 20;98(24):13948-53.

11. Rebel, H., Mosnier, L. O., Berg, R. J., Westerman-de Vries, A., van Steeg, H., van Kranen, H. J., \& de Gruijl, F. R. (2001). Early p53-positive foci as indicators of tumor risk in ultravioletexposed hairless mice: kinetics of induction, effects of DNA repair deficiency, and p53 heterozygosity. Cancer Research 2001;61(3): 977-983.

12. Tabata H, Nagano T, Ray AJ, Flanagan N, Birch-MacHin MA, Rees JL. Low frequency of genetic change in p53 immunopositive clones in human epidermis. $\mathbf{J}$ Invest Dermatol 1999;113(6):972-6.

13. Ratushny, V., Gober, M. D., Hick, R., Ridky, T. W., \& Seykora, J. T. From keratinocyte to cancer: the pathogenesis and modeling of cutaneous squamous cell carcinoma. The Journal of clinical investigation 2012; 122 (2): 464-472.

14. Kasper, M., Jaks, V., Hohl, D., \& Toftgård, R. Basal cell carcinoma-molecular biology and potential new therapies. The Journal of clinical investigation 2012; 122(2): 455.

\section{How to Cite This Article:}

Bidari Zerehpoosh F, Nasiri S, Zahedifard S, Sabeti S. Comparison of P53 Intensity, Frequency and Size in morphologically Normal Skin Periphery of Squamous Cell Carcinoma, Basal Cell Carcinoma And Melanocytic Nevus in Persian Skin Type. Iranian Journal of Pathology. 2017;12(1):62-66. 